\title{
Effects of Cutting after Grafted on Nutrient Uptake of Nasturtium officinale under Selenium Stress
}

\author{
Keqiang Li ${ }^{1, a}$, Lijin Lin ${ }^{2, b}$, Wanwan Xue ${ }^{1, c}$, Xingyu Zhang ${ }^{1, d}$ and Ming'an Liao ${ }^{1, e^{*}}$ \\ ${ }^{1}$ College of Horticulture, Sichuan Agricultural University, Chengdu, Sichuan, China \\ ${ }^{2}$ Institute of Pomology and Olericulture, Sichuan Agricultural University, Chengdu, Sichuan, China \\ a627563308@qq.com, ${ }^{\mathrm{b}}$ llj800924@163.com, ${ }^{\mathrm{c}} 502838055 @ q q . c o m,{ }^{\mathrm{d}} 1640792129 @ q q . c o m$, \\ Iman@sicau.edu.cn
}

${ }^{*}$ Corresponding author. Keqiang Li and Lijin Lin contributed equally to this work.

Keywords: Grafting; cutting; Nutrient uptake; Nasturtium officinale; Selenium

Abstract: To study the effects of cutting after grafted on nutrient uptake of wild vegetables, four rootstocks (Brassica pekinensis, Brassica napus, Raphanus sativus and Rorippa dubia) were used to graft Nasturtium officinale, and then cutting the seedlings of scions and planted in selenium (Se) contaminated soil. The nitrogen $(\mathrm{N})$, phosphorus $(\mathrm{P})$ and potassium $(\mathrm{K})$ uptakes of $N$. officinale were investigated by the pot experiment. The rootstocks of B. pekinensis, B. napus, R. sativus, and R. dubia improved the $\mathrm{N}$ uptake ability of $N$. officinale in Se-contaminated soil, but reduce $\mathrm{K}$ uptake ability of that. The rootstocks of $B$. pekinensis, B. napus, and $R$. sativus increased the $\mathrm{P}$ contents in shoots of $N$. officinale, and the rootstock of $R$. dubia had on significant effects on that. Therefore, the rootstocks of B. pekinensis, B. napus, $R$. sativus, and $R$. dubia could significantly affect the $\mathrm{N}, \mathrm{P}$, and $\mathrm{K}$ uptake of $N$. officinale cutting seedlings after grafted, and the best rootstock was $R$. sativus in Se-contaminated soil.

\section{Introduction}

Since ancient times, people have cut and joined together plants of different varieties or species so they would grow as a single plant--a process known as grafting [1]. Grafting can not only affect the traits, quality and yield of scion, but also enhance the disease resistance, drought resistance, salt tolerance, heat resistance, improve the nutrient uptake function, and promote plant growth [2-4]. Some studies indicate that grafting can limit the uptake of heavy metals in shoots of plants, and increase the absorption of nutrients [5]. Grafting causes the exchanges between the scion and rootstock of two different plants species [6-7], which also leads to the transfer and integration of the genetic material of the rootstock and scion [8-10]. These studies provide a theoretical basis for cutting after grafted to affect plant nutrient uptake under stress conditions.

Selenium (Se) is a special trace element, with low concentrations of Se can promote plant growth, and excess Se is toxic to plants and produces stress on plants [11-13]. In this study, four rootstocks (Brassica pekinensis, Brassica napus, Raphanus sativus and Rorippa dubia) were used to graft Nasturtium officinale (wild vegetable with rapid growth and easy propagation from cuttings), after grafting, the cutting of shoots of $N$. officinale grew in Se contaminated soil, and the effects of nutrient uptake of $N$. officinale were studied. The aim of this study was to screen the best rootstock that could improve the nutrient uptake ability of $N$. officinale in Se-contaminated soil, and provide a reference for other wild vegetables improvement.

\section{Materials and Methods}

Materials. The soil samples used in the experiment were paddy soil that were collected from the Chengdu Campus Farm of the Sichuan Agricultural University $\left(29^{\circ} 59^{\prime} \mathrm{N}, 102^{\circ} 59^{\prime} \mathrm{E}\right)$. The basic soil properties were $\mathrm{pH} 7.42$, organic matter $31.73 \mathrm{~g} / \mathrm{kg}$, total nitrogen $(\mathrm{N}) 1.05 \mathrm{~g} / \mathrm{kg}$, total phosphorus $(\mathrm{P})$ $0.37 \mathrm{~g} / \mathrm{kg}$, total potassium (K) $25.71 \mathrm{~g} / \mathrm{kg}$, alkali-hydrolysable $\mathrm{N} 56.13 \mathrm{mg} / \mathrm{kg}$, available P $17.15 \mathrm{mg} / \mathrm{kg}$, available K $56.65 \mathrm{mg} / \mathrm{kg}$, total Se $0.35 \mathrm{mg} / \mathrm{kg}$. 
The seedlings of $N$. officinale were collected from a ditch in Ya'an, Sichuan, China, and potted in greenhouse of Chengdu Campus of Sichuan Agricultural University. The seedlings of rootstocks $B$. pekinensis, B. napus, $R$. sativus, and $R$. dubia were collected from the Chengdu Campus Farm of the Sichuan Agricultural University, and planted in the pots in June, 2016. $5 \mathrm{~cm}$ stems of rootstock seedlings were selected, and $3 \mathrm{~cm}$ sections of $N$. officinale grafting were used for grafting. When the grafting was completed, the soil moisture content was maintained at $80 \%$ of field capacity, and all of the seedlings were covered with transparent plastic film and a shade net. After $10 \mathrm{~d}$, the transparent plastic film, the shade net and the plastic binding film were removed, and all the germinating buds of rootstocks were also removed.

Experimental Design. The experiment was conducted from November, 2016 to March, 2017 in the greenhouse of Chengdu Campus of Sichuan Agricultural University. Air-dried soil $(3.0 \mathrm{~kg}) \mathrm{was}$ weighed and placed into each polyethylene pot (11 cm high, $22 \mathrm{~cm}$ diamete) in November 2016. Se was added to the soil samples as analytical reagent $\mathrm{Na}_{2} \mathrm{SeO}_{3}$ at the concentration of $10 \mathrm{mg} / \mathrm{kg}$, and then $3 \mathrm{~g}$ of compound fertilizer was applied to each pot and the soil was thoroughly mixed. The soils were soaked in the Se solution for 4 weeks, and then the soil in each pot was mixed thoroughly again. In December 2016, three uniform of $5 \mathrm{~cm}$ length of $N$. officinale branches were cut and transplanted to the pot. Five treatments were applied in the experiment: control (not grafted), and rootstocks of $B$. pekinensis, B. napus, $R$. sativus, and $R$. dubia. Each treatment was repeated six times and completely randomized design with $15-\mathrm{cm}$ spacing between pots. The water depth was $1 \mathrm{~cm}$ higher than the soil surface in the first 2 weeks of the experiment, and $2 \mathrm{~cm}$ above the soil surface from 2 weeks until the time that the $N$. officinale seedlings were harvested. After $60 \mathrm{~d}$ (March 2017), the entire plants of each pot were harvested, the roots, stems and leaves were separated, washed, dried, crushed, and the N, P and $\mathrm{K}$ content were determined [14].

Statistical Analyses. Each treatment used 18 seedlings (repeated six times, 3 seedlings for each repeat) for statistical analyses. Statistical analyses were conducted using SPSS 13.0 statistical software (IBM, Chicago, IL, USA). Data were analyzed by one-way analysis of variance with least significant difference (LSD) at the $\mathrm{p}=0.05$ confidence level.

\section{Results and Discussion}

$\mathbf{N}$ Content in $\mathbf{N}$. officinale. In the Se-contaminated soil, the $\mathrm{N}$ content in roots of $N$. officinale from grafting treatments was significantly higher than those of control (Table 1). The $\mathrm{N}$ content in roots of $N$. officinale treated by rootstock of $R$. sativus was the highest and significantly higher than that of other grafting treatments, and the $\mathrm{N}$ content increased by $31.19 \%(p<0.05)$ compared with the control. The $\mathrm{N}$ content in shoots of $N$. officinale significantly increased by the rootstocks of $B$. pekinensis, B. napus and $R$. sativus, which increased by $15.66 \%(p<0.05), 8.80 \%(p<0.05)$ and $22.91 \%(p<0.05)$ respectively compared with the control. For the whole plants, the $\mathrm{N}$ content in whole plants of $N$. officinale by four grafting treatments was significantly higher than the control, and the rootstock of $R$. sativus was the highest among the grafting treatments. Therefore, the four rootstocks used in this experiment conld improve the $\mathrm{N}$ absorption ability of $N$. officinale in Se-contaminated soil, and the rootstock of $R$. sativus was the best.

$P$ Content in $N$. officinale. In the Se-contaminated soil, the $\mathrm{P}$ content in roots of $N$. officinale were significantly lower than those of the control, but the P content in stems was significantly higher than that of the control (Table 2). The P content in leaves of $N$. officinale was ranked as rootstock of $R$. sativus $>$ rootstock of $B$. pekinensis $>$ rootstock of $B$. napus $>$ control > rootstock of $R$. dubia. The $\mathrm{P}$ contents in shoots of $N$. officinale by the rootstocks of B. pekinensis, B. napus, and $R$. sativus were significantly higher than that of control. The P content in whole plants of $N$. officinale by the rootstock of $R$. sativus was significantly higher than the control, and there were no significant differences between the other grafting treatments and the control. Therefore, the rootstocks of $B$. pekinensis, $B$. napus, and $R$. sativus could improve the P uptake of $N$. officinale in the Se-contaminated soil, and the rootstock of $R$. sativus was the best for the P uptake in whole plants of $N$. officinale. 
Table $1 \mathrm{~N}$ content in $N$. officinale

\begin{tabular}{|l|c|c|c|l|c|}
\hline \multicolumn{1}{|c|}{ Treatments } & $\begin{array}{c}\text { Roots } \\
(\mathrm{mg} / \mathrm{g})\end{array}$ & $\begin{array}{c}\text { Stems } \\
(\mathrm{mg} / \mathrm{g})\end{array}$ & $\begin{array}{c}\text { Leaves } \\
(\mathrm{mg} / \mathrm{g})\end{array}$ & $\begin{array}{c}\text { Shoots } \\
(\mathrm{mg} / \mathrm{g})\end{array}$ & $\begin{array}{c}\text { Whole plants } \\
(\mathrm{mg} / \mathrm{g})\end{array}$ \\
\hline Control & $17.92 \pm 0.45 \mathrm{~d}$ & $15.45 \pm 1.99 \mathrm{~b}$ & $25.02 \pm 2.17 \mathrm{bc}$ & $20.56 \pm 0.98 \mathrm{~d}$ & $19.71 \pm 0.77 \mathrm{c}$ \\
\hline B. pekinensis & $20.87 \pm 0.77 \mathrm{c}$ & $20.63 \pm 1.36 \mathrm{a}$ & $25.76 \pm 2.16 \mathrm{~b}$ & $23.78 \pm 1.80 \mathrm{ab}$ & $22.85 \pm 1.48 \mathrm{~b}$ \\
\hline B. napus & $20.22 \pm 0.58 \mathrm{c}$ & $20.71 \pm 0.71 \mathrm{a}$ & $23.51 \pm 0.89 \mathrm{c}$ & $22.37 \pm 0.78 \mathrm{bc}$ & $21.68 \pm 0.73 \mathrm{~b}$ \\
\hline R. sativus & $23.51 \pm 0.60 \mathrm{a}$ & $20.16 \pm 1.00 \mathrm{a}$ & $28.52 \pm 1.15 \mathrm{a}$ & $25.27 \pm 1.04 \mathrm{a}$ & $24.76 \pm 0.92 \mathrm{a}$ \\
\hline R. dubia & $22.19 \pm 0.79 \mathrm{~b}$ & $16.28 \pm 1.09 \mathrm{~b}$ & $24.68 \pm 0.62 \mathrm{bc}$ & $21.51 \pm 0.76 \mathrm{~cd}$ & $21.70 \pm 0.76 \mathrm{~b}$ \\
\hline
\end{tabular}

Values are means \pm standard errors. Means with the same letter within each column are not significantly different at $p<0.05$.

Table $2 \mathrm{P}$ content in $N$. officinale

\begin{tabular}{|l|c|c|c|c|c|}
\hline \multicolumn{1}{|c|}{ Treatments } & $\begin{array}{c}\text { Roots } \\
(\mathrm{mg} / \mathrm{g})\end{array}$ & $\begin{array}{c}\text { Stems } \\
(\mathrm{mg} / \mathrm{g})\end{array}$ & $\begin{array}{c}\text { Leaves } \\
(\mathrm{mg} / \mathrm{g})\end{array}$ & $\begin{array}{c}\text { Shoots } \\
(\mathrm{mg} / \mathrm{g})\end{array}$ & $\begin{array}{c}\text { Whole plants } \\
(\mathrm{mg} / \mathrm{g})\end{array}$ \\
\hline Control & $6.31 \pm 0.26 \mathrm{a}$ & $15.02 \pm 1.70 \mathrm{~b}$ & $5.09 \pm 0.08 \mathrm{c}$ & $9.49 \pm 0.28 \mathrm{~b}$ & $8.46 \pm 0.23 \mathrm{bc}$ \\
\hline B. pekinensis & $5.15 \pm 0.28 \mathrm{~d}$ & $17.69 \pm 1.54 \mathrm{a}$ & $5.28 \pm 0.16 \mathrm{~b}$ & $10.07 \pm 0.62 \mathrm{a}$ & $8.48 \pm 0.52 \mathrm{bc}$ \\
\hline B. napus & $5.55 \pm 0.15 \mathrm{c}$ & $17.62 \pm 1.02 \mathrm{a}$ & $5.11 \pm 0.13 \mathrm{c}$ & $10.21 \pm 0.45 \mathrm{a}$ & $8.70 \pm 0.37 \mathrm{ab}$ \\
\hline R. sativus & $6.00 \pm 0.21 \mathrm{~b}$ & $17.25 \pm 0.69 \mathrm{a}$ & $5.68 \pm 0.17 \mathrm{a}$ & $10.18 \pm 0.38 \mathrm{a}$ & $8.96 \pm 0.34 \mathrm{a}$ \\
\hline R. dubia & $5.48 \pm 0.12 \mathrm{c}$ & $16.54 \pm 0.69 \mathrm{a}$ & $4.82 \pm 0.12 \mathrm{~d}$ & $9.25 \pm 0.37 \mathrm{~b}$ & $8.16 \pm 0.30 \mathrm{c}$ \\
\hline
\end{tabular}

Values are means \pm standard errors. Means with the same letter within each column are not significantly different at $p<0.05$.

K Content in $\mathbf{N}$. officinale. The K contents in roots and whole plants of $N$. officinale by grafting treatments were significantly lower than those of control in Se-contaminated soil (Table 3). However, the K content in whole plants of $N$. officinale by the root stock of $R$. sativus was significantly higher than that of the other three grafting treatments. There were no significant differences of $\mathrm{K}$ contents in stems of $N$. officinale by the rootstocks of $R$. sativus and $R$. dubia, while the K content in stems of $N$. officinale by the rootstocks of $B$. pekinensis and B. napus were significantly lower than the control. The K contents in leaves and shoots of $N$. officinale by grafting treatments were lower than those of the control except the rootstock of $R$. sativus. Therefore, in the Se-contaminated soil, the four rootstocks (B. pekinensis, B. napus, $R$. sativus, and $R$. dubia) could reduce the $\mathrm{K}$ uptakes in $N$. officinale.

Table $3 \mathrm{~K}$ content in N. officinale

\begin{tabular}{|l|c|c|c|c|c|}
\hline \multicolumn{1}{|c|}{ Treatments } & $\begin{array}{c}\text { Roots } \\
(\mathrm{mg} / \mathrm{g})\end{array}$ & $\begin{array}{c}\text { Stems } \\
(\mathrm{mg} / \mathrm{g})\end{array}$ & $\begin{array}{c}\text { Leaves } \\
(\mathrm{mg} / \mathrm{g})\end{array}$ & $\begin{array}{c}\text { Shoots } \\
(\mathrm{mg} / \mathrm{g})\end{array}$ & $\begin{array}{c}\text { Whole plants } \\
(\mathrm{mg} / \mathrm{g})\end{array}$ \\
\hline Control & $32.12 \pm 0.92 \mathrm{a}$ & $43.61 \pm 1.83 \mathrm{a}$ & $26.59 \pm 3.26 \mathrm{a}$ & $34.12 \pm 2.89 \mathrm{a}$ & $33.50 \pm 2.00 \mathrm{a}$ \\
\hline B. pekinensis & $18.97 \pm 0.82 \mathrm{~d}$ & $39.70 \pm 2.54 \mathrm{~b}$ & $22.51 \pm 1.67 \mathrm{~b}$ & $29.15 \pm 1.89 \mathrm{~b}$ & $25.86 \pm 1.58 \mathrm{c}$ \\
\hline B. napus & $26.61 \pm 0.70 \mathrm{c}$ & $39.12 \pm 0.82 \mathrm{~b}$ & $17.76 \pm 0.78 \mathrm{c}$ & $26.46 \pm 0.85 \mathrm{c}$ & $26.51 \pm 0.80 \mathrm{c}$ \\
\hline R. sativus & $25.74 \pm 0.77 \mathrm{c}$ & $44.29 \pm 0.83 \mathrm{a}$ & $24.68 \pm 0.80 \mathrm{a}$ & $32.30 \pm 0.90 \mathrm{a}$ & $30.40 \pm 0.88 \mathrm{~b}$ \\
\hline R. dubia & $29.37 \pm 0.65 \mathrm{~b}$ & $42.74 \pm 0.98 \mathrm{a}$ & $16.59 \pm 0.99 \mathrm{c}$ & $26.47 \pm 0.95 \mathrm{c}$ & $27.31 \pm 0.85 \mathrm{c}$ \\
\hline
\end{tabular}

Values are means \pm standard errors. Means with the same letter within each column are not significantly different at $p<0.05$.

\section{Conclusions}

Different rootstocks (B. pekinensis, B. napus, R. sativus, and $R$. dubia) for grafting could affect the nutrient uptake of $N$. officinale cuttings in Se-contaminated soil, and the effects of nutrient uptake were different by different rootstocks. The rootstocks of B. pekinensis, B. napus, R. sativus, and $R$. dubia improved the $\mathrm{N}$ uptake ability of $N$. officinale in Se-contaminated soil, but reduce $\mathrm{K}$ uptake ability of that. The rootstocks of B. pekinensis, B. napus, and $R$. sativus increased the $\mathrm{P}$ contents in 
shoots of $N$. officinale, and the rootstock of $R$. dubia had on significant effects on that. Therefore, the rootstocks of $B$. pekinensis, B. napus, $R$. sativus, and $R$. dubia could significantly affect the N, P, and $\mathrm{K}$ uptake of $N$. officinale cutting seedlings after grafted, and the best rootstock was $R$. sativus in Se-contaminated soil.

\section{Acknowledgements}

This work was financially supported by the Undergraduate Student Research Interesting Training Program of Sichuan Agricultural University (2016).

\section{References}

[1] C.W. Melnyk and E.M. Meyerowitz: Current Biology Vol. 25 (2015), p. 183.

[2] R.M. Rivero, J.M. Ruiz and L. Romero: Journal of Food Agriculture \& Environment Vol. 1 (2003), p. 70.

[3] R.M. Rivero, J.M. Ruiz and L. Romero: Journal of the Science of Food \& Agriculture Vol. 83 (2003), p. 1315.

[4] E. Sánchez-Rodríguez, L. Romero and J.M. Ruiz: Journal of Plant Growth Regulation Vol. 32 (2013), p. 831.

[5] D. Savvas, G. Colla, Y. Rouphael, D. Schwarz and G. Colla: Scientia Horticulturae Vol. 127 (2010), p. 156.

[6] J.S. Cheng: Garden Plant Genetics and Breeding (China Forestry Publishing House, Beijing 2000).

[7] Y.C. Guan: Acta Agronomica Sinica Vol. 26 (2000), p. 975.

[8] Y. Ohta: Euphytica Vol. 55 (1991), p. 91.

[9] Y. Hirata: Japanese Journal of Breeding Vol. 30 (1980), p. 83.

[10] D. Zhang, Z. Meng, W. Xiao, X. Wang and Sodmergon: Acta Botanica Sinica Vol. 44 (2002), p. 832.

[11] S.D. Gregorio, S. Lampis, F. Malorgio, G. Petruzzelli, B. Pezzarossa and G. Vallini: Plant \& Soil Vol. 285 (2006), p. 233.

[12] P.A. Biacs, H.G. Daood and I. Kadar: Journal of Agricultural \& Food Chemistry Vol. 43 (1995), p. 589.

[13] B. Pezzarossa, G. Petruzzelli, F. Petacco, F. Malorgio and T. Ferri: Chemosphere Vol. 67 (2007), p. 322.

[14] S.D. Bao: Agrochemical Soil Analysis (3rd edition, China Agriculture Press, Beijing 2000). 